\title{
The provision of bioinformatics services in Canadian academic libraries ${ }^{1}$
}

\author{
Danielle Dennie
}

\begin{abstract}
Introduction - This article describes the level of bioinformatics services offered by academic libraries across Canada. It also assesses faculty use of bioinformatics resources and the need for library bioinformatics services at one academic institution, Concordia University. Methods - To assess the level of bioinformatics services at Canadian universities, a survey was sent to life and health sciences librarians at English-speaking Canadian universities comparable to Concordia University. To assess faculty use of bioinformatics and the need for bioinformatics instruction, another survey was sent to faculty of the Centre for Structural and Functional Genomics at Concordia University. Results - Approximately one-quarter of librarians surveyed provided services such as online research guides for bioinformatics resources, workshops, or online tutorials. Individual consultations with students were infrequent. The majority of the libraries where bioinformatics services were offered were at universities with a medical school. The faculty survey indicated that Concordia Centre for Structural and Functional Genomics researchers are heavy users of bibliographic and bioinformatics databases, using at least one of these databases on a daily basis. Most faculty members learned how to use bioinformatics databases on their own and regularly teach the use of these databases to their students or colleagues. Nevertheless, faculty at Concordia seem to be open to some form of collaboration with the library for the provision of bioinformatics services. Discussion - Although librarians can participate in the teaching of bioinformatics database skills, library services in bioinformatics at Canadian university libraries are still in the embryonic phase. Librarians should be trained in the use of these databases to increase their confidence and expertise and to help them market these skills to faculty and students.
\end{abstract}

\section{Introduction}

Over the past two decades, genomics, the study of all the genes found in an organism [1], has been responsible for explosive growth in the generation of biological information. "This deluge of genomic information [requires] computerized databases to store, organize, and index the data and for specialized tools to view and analyze the data" [2]. This type of handling of DNA and protein sequence data is a relatively new field of study called bioinformatics. Given the field's essential reliance on databases, it would seem to make collaborations with libraries and librarians on the use of these databases a natural fit. However, studies have shown otherwise. In fact, the provision of library services such as instruction or consultation in the field of bioinformatics is embryonic. Bartlett [3] found that members of research groups learned how to use bioinformatics databases through informal instruction by colleagues who were the most knowledgeable about these resources. Another study by Brown [4] on the use of bioinformatics databases by molecular biology graduate students showed that $92 \%$ of those surveyed used these databases on a regular basis to search for sequences or to compare their data with that of others. However, when asked how they learned about the databases, the majority reported having learned from their graduate supervisor, in a class, or from other students. The library or librarians were never listed as the source for this knowledge. Brown thus concludes that students in molecular biology overlook the library as an "information ground" or "information community" in favour of their mentors or colleagues in the laboratory.

It is clear from Brown's study [4] that the use of bioinformatics databases, such as GenBank, OMIM, and BLAST, is being taught in universities. The American Society for Biochemistry and Molecular Biology (ASBMB), in their recommended biochemistry and molecular biology undergraduate curriculum, lists the use of computer databases and bioinformatics as core content [5]. In fact, Dinkelman [6] points to a series of articles published in the life sciences pedagogical literature where instruction on the use of these databases is incorporated into the undergraduate curriculum. However, she notes that this literature never alludes to faculty-librarian collaborations as an effective means of database instruction. This does not mean that collaborations do not exist, but studies seem to indicate that they are uncommon.

For example, one study by Messersmith et al. [7] looked at the frequency of faculty-librarian bioinformatics collaboration in the United States, or more specifically, the extent of library bioinformatics workshops as a form of end-user support in that field. The authors reviewed 239 American

D. Dennie. Concordia University, Vanier Library, 7141 Sherbrooke St. West, Montréal, QC H4B 1R6, Canada (e-mail: danielle.dennie@ concordia.ca).

${ }^{1}$ This paper has been peer-reviewed. 
university websites to see if bioinformatics workshops were offered either by the library, by a bioinformatics centre, or by other facilities. Only $15(6.5 \%)$ of all libraries at these universities were involved in providing bioinformatics workshops. The percentage was lower if universities with medical schools were removed from the analysis. What is more interesting is that bioinformatics liaison librarians were responsible for teaching all 15 workshops, and that these specialists offered a complement of other bioinformatics services such as research guides, class specific instruction, reference and consultation services, and collection development.

Much of the literature on the provision of library services in the field of bioinformatics is written by these bioinformatics liaison librarians who in most cases have advanced degrees (usually a Ph.D.) in the life sciences [8-12]. This specialization may be very important when reaching out to faculty. Rein [9] describes how at Purdue University, scientists for whom bioinformatics library services were created felt that librarians may not have the knowledge or training required to comprehend bioinformatics research.

Nevertheless, the lack of an advanced degree in the biological sciences should not deter librarians from offering library services in this field. To this end, Kajosalo [13] identifies three service levels that libraries can offer. The basic level requires that librarians have some knowledge of bioinformatics databases, as well as the ability to locate bioinformatics resources and offer introductory training programs. At this level of service, librarians would also perform collection development in the field and curate a portal of bioinformatics web resources. A librarian with a Masters degree in information studies should have the necessary skills to offer this level of service. The intermediate level requires that at least some librarians have the ability to answer reference or instructional questions, such as how to identify appropriate tools for research. This level of service offers course-integrated instruction, one-on-one consultation services, and provides the ability to negotiate database licensing. Having the ability to provide these services would require staying current with the evolution of bioinformatics resources, both theoretically and through practice. Finally, the expert level requires a specialist in the library who could handle analytical questions such as how to plan experiments or offer in-depth assistance with data analysis. This type of service would be offered by dedicated specialist(s), not necessarily librarians, with a bioinformatics or a cheminformatics background.

Yarfitz and Ketchell [12] looked at bioinformatics questions at the University of Washington Health Sciences Libraries and found that at least $90 \%$ of the questions could be answered by librarians with training in the use of bioinformatics tools and databases: $15 \%$ of the questions were basic, directional, questions that focused on how to locate resources, programs, or databases; and $75 \%$ of inquiries, labelled technical questions by the authors, were in fact traditional reference or instructional questions. These questions involved helping users identify appropriate databases or programmes for a specific task. The last $10 \%$ of questions were mostly analytical or expert level questions, as described by Kajosalo [13] (see the previous paragraph). From the Yarfitz and Ketchell study [12], it can be assumed that the majority of bioinformatics-related questions can be answered by librarians without advanced degrees in the biological sciences but with sufficient training in bioinformatics resources.

Following this assumption, the development of library bioinformatics services should be feasible. To this end, Geer [14] provides a series of useful suggestions:

- The reference desk staff should be trained to answer directional questions and to refer reference or instructional questions to the appropriate librarian specialist.

- A web portal should be created providing a space where bioinformatics tools and databases could be listed as well as news pertaining to the provision of library services in the field.

- Workshops should be provided for a variety of resources and for a variety of audiences. More specifically, curriculum-integrated instruction should be proposed to the relevant professors.

- In addition, one-on-one consultations should be available to students and faculty alike.

- Finally, evaluating, selecting, licensing, and providing technical assistance for bioinformatics databases would be helpful.

Most of the articles written on bioinformatics services in academic libraries were published prior to 2007 and pertain to services offered in libraries in the United States. Therefore, the first objective of this study was to examine bioinformatics services provided by libraries in Canadian universities using Geer's [14] recommendations listed above. Furthermore, since the study by Messersmith et al. [7] indicated that the provision of bioinformatics services in academic libraries in the United States was more common at universities with medical schools, particular attention was also paid to evaluate whether this finding equally applied in the Canadian context. The second objective of this study was to establish the need for bioinformatics services in one academic setting: Concordia University, in Montréal, Quebec. In the fall of 2009, Concordia University announced its plans to invest nearly $\$ 30$ million dollars in the Centre for Structural and Functional Genomics [15]. This centre will house researchers from multiple departments and may require additional support from the library, which, as of yet, has not developed elaborate services in the field of bioinformatics.

To accomplish these objectives a survey was sent to librarians who are potential bioinformatics service providers in Canadian academic libraries and whose responsibilities lie in the biological or health sciences. The results of this study will hopefully provide direction to all Canadian librarians who wish to develop services for students and faculty in bioinformatics.

To assess the bioinformatics needs of stakeholders who could benefit from library services in this field, a second survey was sent to the faculty members of the Centre for Structural and Functional Genomics at Concordia University to establish their use of, and desire for, instruction in bioinformatics tools and databases. This survey would help to assess whether the bioinformatics needs of faculty and their students are fulfilled at Concordia University and whether services could be developed to address their needs. 


\section{Methodology}

\section{Librarian survey}

To survey librarians across Canada, 21 universities with a student population similar to that of Concordia University were chosen in English Canada (given possible cultural differences that could impact service provision, universities in Quebec were not sampled). Library websites for the 21 universities were visited to gather the names and contact information of librarians whose subject responsibilities were in the biological or health sciences. Subject responsibilities included biology, biochemistry, molecular biology, cell biology, genetics, microbiology, plant science, biotechnology, biological engineering, and medicine. In October 2009, a total of 57 librarians were contacted individually by e-mail. A link to a SurveyMonkey survey was provided. The survey was designed to assess whether (1) the level of bioinformatics services offered were similar to those suggested by Geer [14] above and whether (2) librarians working in universities with medical schools provided a greater number of bioinformatics services, as suggested by Messersmith et al. [7]. Survey responses were anonymous. The survey is presented in Appendix A. A list of the universities contacted is presented in Appendix B.

\section{Faculty survey}

To survey members of the Concordia University Centre for Structural and Functional Genomics, individual e-mails were sent to the 22 faculty members listed on the Centre's website to ask them to fill out a survey on their use of bioinformatics tools and resources. This survey was also sent in October 2009. The design of the survey was modeled on the one prepared by Brown [4] in her study on the use of bioinformatics databases by graduate students in molecular biology. Survey responses were anonymous. The survey is presented in Appendix C.

\section{Results}

\section{Librarian survey}

A total of 32 librarians responded to the survey ( $56 \%$ response rate). Of the librarians who responded, $69 \%(n=22)$ have a formal education in the sciences. From this subset, $36 \%(n=8)$ have an undergraduate degree and $64 \%(n=14)$ have a graduate degree. Degrees were in the following subject areas: engineering, physics, mathematics, organic chemistry, medicine, nursing, optometry, biosystematics, biology, anatomy, zoology, insect physiology, vertebrate morphology, geology, earth sciences, oceanography, and psychology.

Of all the librarians who responded, $69 \%(n=22)$ work at a university where there is a medical school. Also, none of the librarians listed bioinformatics as one of their subject or liaison responsibilities.

Table 1 summarizes the responses to the questions on the provision of library services in bioinformatics. The results indicate that $19 \%(n=6)$ of librarians reported having provided class-specific bioinformatics workshops. However, if only respondents from universities with medical schools are considered, the percentage increases to $23 \%$. Only $6 \%(n=2)$ of librarians reported giving general bioinformatics workshops not connected to classes. These two librarians also provided specific workshops for classes. Finally, only one librarian had created online bioinformatics tutorials. Another respondent indicated that although their library had not created their own tutorials, they were currently running a trial on Open Helix, a subscription resource of online bioinformatics tutorials and assessing student and faculty need for this tool.

A larger percentage of librarians, $25 \%(n=8)$, had created bioinformatics research guides. The majority of these librarians worked at a university where there was a medical school and five of them had provided a bioinformatics workshop for a class. Finally, a total of $32 \%(n=10)$ of all respondents had received questions from students and faculty regarding bioinformatics resources. The questions were, however, very infrequent. A few librarians commented on the reasons why there was very little provision of bioinformatics library services at their library:

- "At our university, faculty \& grad students teach how to use these types of databanks - not librarians."

- "I don't have the training/experience to answer the questions related to bioinformatic questions."

- "Our faculty have indicated that the library refer students to them if the questions are coming from students in a particular course."

- "Over the years, we've talked about supporting students in bioinformatics, and I've even taken a 3 day training course but there's never been demand. It seems like folks in the labs support each other in the use of the genetics/ protein databases."

\section{Faculty survey}

A total of 12 out of the 22 faculty members responded to the survey $(54.5 \%$ response rate). Their fields of study were biochemistry, cell and molecular biology, plant biology, microbiology, bioinformatics, and genomics. Biochemistry was the field of study most frequently mentioned $(50 \%, n=6)$.

PubMed was the most frequently consulted database: $83 \%(n=10)$ of faculty members reported consulting it daily. Web of Science and SciFinder were the next databases used most. The majority of Web of Science users $(42 \%, n=5)$ consulted the database monthly; whereas, SciFinder was mostly consulted weekly $(33 \%, n=4)$. Faculty members who listed biochemistry as their field of study use the Web of Science and SciFinder databases most frequently. BIOSIS and INSPEC were the least used of all the databases. Interestingly, one biochemistry faculty member indicated in the "Other databases" field that he (or she) browses references in the Protein Data Bank on a daily basis. Figure 1 shows all responses for the frequency of bibliographic database consultation.

All respondents of the survey use bioinformatics tools and resources with 100\% $(n=12)$ using at least one resource weekly. BLAST and GenBank are the most frequently used tools and databases; both being used daily or weekly by $83 \%(n=10)$ of faculty members. SWISS-PROT and Protein Data Bank follow close behind with consultations daily or weekly, by $75 \%(n=9)$ and $58 \%(n=7)$ of faculty members, respectively. TrEMBL is the least frequently used, with only $42 \%(n=5)$ of faculty members 
Table 1. Librarian responses to survey questions on the provision of library services in bioinformatics.

\begin{tabular}{|c|c|c|c|}
\hline Question & Yes* & No & Comments (from the "Yes" category) \\
\hline $\begin{array}{l}\text { Do you provide general library workshops, } \\
\text { not connected to any university course, in } \\
\text { the use of bioinformatics databases or } \\
\text { resources (such as GenBank or Swiss- } \\
\text { Prot)? }\end{array}$ & $2(1)$ & 30 & $\begin{array}{l}\text { OMIM, and the use of BLAST, gene, protein, } \\
\text { Searching Entrez }\end{array}$ \\
\hline $\begin{array}{l}\text { Have you created online tutorials that show } \\
\text { how to use bioinformatics databases or } \\
\text { resources (such as GenBank or Swiss- } \\
\text { Prot)? }\end{array}$ & $1(1)$ & 31 & OMIM, BLAST and ProtParam \\
\hline $\begin{array}{l}\text { Do you maintain a research guide or } \\
\text { webpage specifically on bioinformatics } \\
\text { which would contain information about } \\
\text { resources and tools, services and } \\
\text { workshops, etc.? }\end{array}$ & $8(7)$ & 24 & \\
\hline $\begin{array}{l}\text { Do you receive questions from students or } \\
\text { faculty who may need help finding or } \\
\text { using bioinformatics databases or } \\
\text { resources? }\end{array}$ & $10(9)$ & 22 & $\begin{array}{l}\text { Questions received monthly: } 5 \\
\text { Questions received yearly: } 5\end{array}$ \\
\hline
\end{tabular}

*Numbers in parentheses indicate the number of respondents who work at universities with medical schools.

consulting it daily or weekly. Some faculty members also indicated using other databases. For example, one respondent uses BRENDA (an enzyme database) and Amigo (a gene ontology database) on a daily basis, as well as CAZy (Carbohydrate-Active Enzymes) and KEGG (Kyoto Encyclopedia of Genes and Genomes) on a weekly basis. Another respondent uses ExPASy (a proteomics database) on a daily basis. Figure 2 shows all

Fig. 1. Frequency with which 12 faculty members from Concordia University Centre for Structural and Functional Genomics consult bibliographic databases.

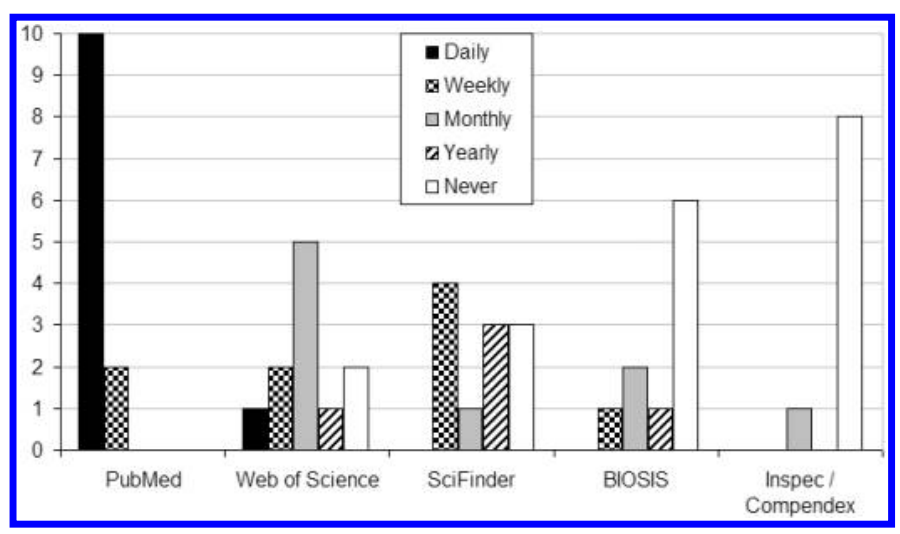

responses for the frequency of bioinformatics tools and database consultation.

To the question "why do you access Web-based bioinformatics database(s)?", $50 \%(n=6)$ responded that they access the databases to deposit data, and $92 \%(n=11)$ responded that they use the databases both to compare their data with that of other laboratories and to look for newly deposited sequences and structures from other laboratories.

Fig. 2. Frequency with which 12 faculty members from Concordia University Centre for Structural and Functional Genomics use bioinformatics tools and databases. Do changes preserve your meaning?

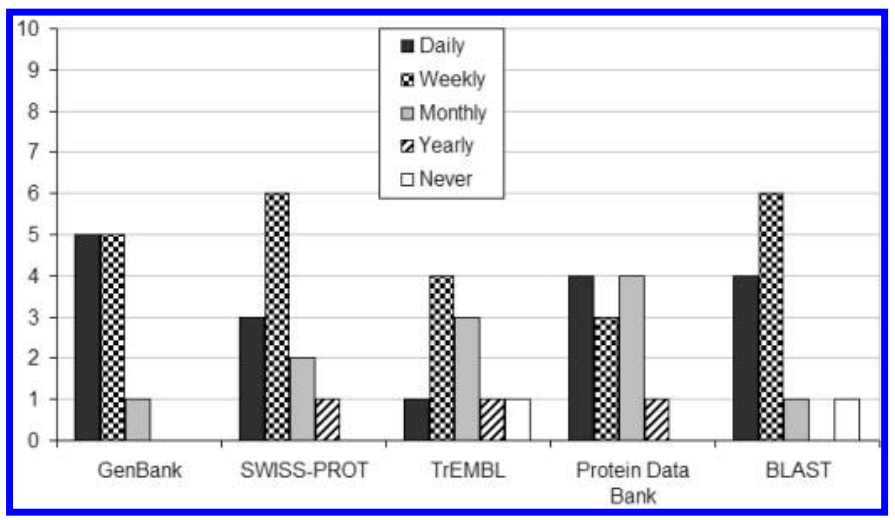


To the question "where did you learn how to use bioinformatics databases?" the respondents said that they learned on their own, $(67 \%, n=8)$, and (or) from colleagues, $(67 \%, n=8)$. These colleagues include graduate students $(25 \%, n=3)$, postdoctoral fellows $(25 \%, n=3)$, or professors during classes in their graduate or undergraduate studies $(17 \%, n=2)$. One member listed learning from reading scientific articles. None of the respondents listed a librarian as someone who taught them how to use these databases.

To the question "to whom have you taught the use of bioinformatics databases", $100 \%(n=12)$ indicated teaching it to the graduate or undergraduate students that they supervise in their laboratories, $67 \%(n=8)$ have taught it to their colleagues and $75 \%(n=9)$ taught these databases to students in classes at the graduate or undergraduate level. Finally, 50\% $(n=6)$ indicated that they had taught the use of these databases or tools to technicians in their laboratories.

Finally, to the question "do you believe the library should play a role in training or consulting with students or faculty in the use of bioinformatics databases (for example, by giving workshops or helping individual students with questions they may have)", $58 \%(n=7)$ responded in the affirmative, while $33 \%(n=4)$ said no. Of the respondents who were not in favour of the library being involved in training, one indicated that "expertise might be insufficient"; whereas, another said "I think students should learn this in the context of their regular classes." Other comments include the following:

- "Any help would be useful. Pubmed [sic] instruction is helpful for the students. For the use of data bases, I have some doubt that the library would have the expertise to train students. If you could develop it, I would support it. I teach bioinformatics, I would be willing to participate in the development of a free standing system such as tutorials-on-line."

- "Bioinformatics is an integral and important part of life science and its importance will only increase. Knowledge on the effective use of these databases and their limitation (e.g., accuracy of the source of data) is extremely useful for understanding complex biological problems."

- "I would doubt that someone at the library would have the depth of knowledge needed for in-depth research; certain aspects could certainly be covered for undergraduates, but I think I would have to be convinced that the library was the right place to deliver this. It would certainly be worth discussing working cooperatively."

- "For a science library this would be really progressive. Even if we cover in some courses, it pays to have it reinforced."

- "No workshops please; one on one"

\section{Discussion}

The provision of library services in the field of bioinformatics in Canadian universities is still in an embryonic state. This study looked at the levels of services that can be provided, as described in Geer's article [14]. These include class workshops, general workshops, online tutorials, online subject guides, and individual consultations. The most common type of service provided was individual consultations, with $32 \%$ of librarians having provided this service in the past, although these consultations happened infrequently. Online research guides in bioinformatics were also common, with $25 \%$ of respondents providing this service. Finally, the other types of services, such as workshops or online tutorials, were provided by less than $20 \%$ of librarians.

The generally low level of library involvement in bioinformatics services was also reflected in the fact that not one librarian surveyed listed bioinformatics as being their subject or liaison responsibility. A few of the librarians surveyed also commented that, help and instruction in the use of these tools and resources occurs in the faculties and that librarians may not have the necessary expertise to deliver service in this area.

Nonetheless, it was interesting to note that the majority of Canadian librarians surveyed (69\%) had science degrees. In Winston's [16] review of the literature on the educational backgrounds of librarians in science and engineering libraries, surveys in the 1980s and 1990s indicate that between $18 \%$ and $67 \%$ of librarians have some kind of university science degree. A study by Hackenberg and Chu [17] on the academic backgrounds of science librarians showed that librarians:

with a science background hold an advantage and can step into a sci-tech position feeling confident from day one depending on the library setting they are in and how well matched they are with the position description. This idea is supported by Stuart and Drake (1992), "The science or engineering degreed librarian with a grounding in subject material, practice in scientific and research methods, and a presumed enthusiasm for the subject discipline is more likely to establish valuable relationships with clients and be able to provide effective information services."

Even though the librarians surveyed in this study may not have much experience in bioinformatics, their science degrees could be used to promote their understanding of scientists' needs. In fact, in the survey of Concordia University faculty members, a majority of faculty members seemed open to library services in the field of bioinformatics. This may be due, in part, to their awareness of the author's science degrees. Only 2 out of the 12 respondents commented that the librarian's knowledge may be insufficient.

On the other hand, faculty-librarian collaborations in this field may be influenced by other factors. Interestingly, Messersmith et al. [7] showed that the presence of a medical school is positively correlated with the provision of library services in bioinformatics. Their study found that, of the 239 American university websites examined, only $6.5 \%$ of the libraries provided bioinformatics workshops; however, this total increased to $10.7 \%$ if the university had a medical school. In this respect, this study on Canadian university libraries seems to corroborate the findings of Messersmith et al. since the majority of universities where workshops and other services were provided by librarians had medical schools. It may be that medical schools have a stronger history of faculty-librarian collaborations, because many medical schools have a dedicated medical or science library with health sciences librarians who may work as a team to develop services. It may also be that these schools offer more genetics or molecular biology classes, which lend themselves well to bioinformatics workshops. 
Faculty-librarian collaborations in the biology department at Concordia are slowly evolving but require more outreach strategies such as offering workshops and one-onone consultations or creating tutorials. One explanation for the lack of library involvement in bioinformatics services is that since surveyed faculty members are avid users of bioinformatics and literature databases, they may consider their database searching skills and knowledge of the discipline better suited to teach these resources to students. Another possibility is that since many of them learned on their own $(67 \%)$ or were taught in a collaborative laboratory setting, they may expect the same type of learning from their students.

The results of the survey of Concordia faculty members regarding their substantial use of literature and bioinformatics databases differ from those of Brown's study [18]. Brown looked at the use of bioinformatics and literature databases by molecular biology, biochemistry, and biomedical faculty and post-doctoral fellows at the University of Oklahoma. Brown found that $46 \%$ access MEDLINE on a daily or weekly basis whereas at Concordia, $100 \%$ of respondents use PubMed daily or weekly. Perhaps the use of the word MEDLINE in her survey confused the respondents, as she indicated that a few scientists listed PubMed in the "other databases used" category. Brown's study also found that $52 \%$ of respondents access bioinformatics databases daily or weekly. At Concordia, once again, $100 \%$ of respondents use at least one of the bioinformatics databases daily or weekly. One reason for the differences in use may be that Brown's study was conducted in the early 2000s when use of online databases may have been less prevalent. The different results may also reflect that Concordia University survey participants were chosen specifically because they were part of a genomics research centre. Bioinformatics tools are usually a necessary part of their research, which would therefore have some bearing on the survey results. If all teaching faculty in the biochemistry and biology departments at Concordia University were surveyed, the results may have been closer to those obtained by Brown.

Although faculty members surveyed here use literature and bioinformatics databases abundantly, the effectiveness of their search skills remains unknown. Geer [14] showed in her study that $70 \%$ of searches in Entrez were done as simple queries without field specifiers, Boolean operators, or other advanced search techniques. This was even more pronounced in specific databases such as Entrez Protein where $89 \%$ of queries were simple searches. Geer notes that "these kinds of statistics bring into question how well most users understand the scope of a particular data domain and the software features that can help them to hone their search precisely to their needs and how effectively or efficiently they are currently mining the data" [14]. These results reinforce the idea that librarians, who already have instructional experience and expertise in searching complex databases, have excellent potential to develop data mining expertise in bioinformatics as well as provide instruction on how to use bioinformatics tools and databases. In addition, librarians should market their skills more energetically to faculty and students.
Whether or not the faculty members at Concordia are effective searchers, many of them are teaching bioinformatics tools and resources to their students in classes. At Concordia, there is a graduate class in bioinformatics (BIOL 510) that covers the use of these databases. Therefore, the need for inclass library workshops at Concordia at the graduate level may be less important than providing guidance in the form of online research guides, tutorials, and one-on-one consultations. Furthermore, cooperating with faculty in developing workshops for undergraduate students may be more practical. In a preliminary survey sent to graduate students in biology and biochemistry at Concordia University, one student made the following comment:

\begin{abstract}
Ideally, instruction would be wonderful, however, as with many people, my research needs are unique to me. After taking a bioinformatics course I found only a small fraction of the programs covered over the term to be useful. I would be very interested in two possibilities. A brief and general overview of 'what is out there'. And the ability to have detailed instructions on specific programs and (or) clusters of programs grouped in concepts, such as programs good for looking at: protein interactions, sequence similarity, structural and motif predictions, whole genome sequences and mapping.
\end{abstract}

\section{Conclusion}

At Concordia University, like at most universities across Canada, science librarians, present and past, have been reluctant to provide library services in bioinformatics. To overcome this tendency, additional bioinformatics training is needed to develop confidence when discussing bioinformatics services with faculty. Also, the creation of online research guides in bioinformatics, as well as online tutorials on effective searching techniques, could be a good outreach tool to inform faculty of a librarian's level of understanding about these tools and resources. Additionally, Lyon et al. [19] recommend finding "initial advocates on the faculty and research staff who are library supporters, particularly those who champion bioinformatics education (e.g., at the undergraduate level). They can serve as an entry point into the research community." The faculty survey at Concordia University indicates that the majority of professors surveyed were open to collaborations with the library.

\section{Limitations and directions for future research}

The anonymity of the library survey made it impossible to know whether there were clusters of responses from particular universities. Thus, it is possible that certain universities weighted the results in a particular direction.

As for the faculty survey, the responses may have been biased since the author is well known by many of those surveyed. A larger study on bioinformatics researchers' perceptions of the library's role in bioinformatics would be beneficial. To complement this area of study, an investigation into the bioinformatics database search skills of students and faculty could help to elucidate why the majority of searches in Entrez are simple queries that do not take advantage of advanced search techniques [14]. 


\section{References}

1. The Oxford Dictionary of English [December]. 2nd ed. Oxford (UK): Oxford University Press; c2005 [cited 2010 May 10]. Available from http://www.oxfordreference.com/views/ENTRY. html? subview $=$ Main\&entry $=$ t140.e30993.

2. National Center for Biotechnology Information [December]. Bethesda: NCBI; 2010 [updated 2004 Mar 29; cited 2009 Nov 23]. A Science Primer: Bioinformatics; [about 6 screens]. Available from http://www.ncbi.nlm.nih.gov/About/primer/ bioinformatics.html.

3. Bartlett J. The oral tradition of bioinformatics expertise. In: Toms EG, editor. Information, connections and community. ASIST Proceedings of the 65th Annual Meeting of the American Society for Information Science and Technology (vol. 39); 2002 Nov 18-21, Philadelphia, Pennsylvania. Medford, NJ: Information Today, Inc.; 2002. pp. 452-3.

4. Brown C. Where do molecular biology graduate students find information? Science \& Technology Libraries. 2005;25(3):89104. doi: 10.1300/J122v25n03_06.

-5. Voet JG, Bell E, Boyer R, Boyle J, O’Leary M, Zimmerman JK. Recommended curriculum for a program in biochemistry and molecular biology. Biochem Mol Biol Educ. 2003;31(3): 161-2. doi: 10.1002/bmb.2003.494031030223.

6. Dinkelman AL. 'See a need, fill a need' - reaching out to the bioinformatics research community at Iowa state university. ISTL. 2007 Fall [cited 2009 Nov 30]; 52 [about 13 pp.]. Available from: http://www.istl.org/07-fall/refereed1.html.

7. Messersmith DJ, Benson DA, Geer RC. A web-based assessment of bioinformatics end-user support services at US universities. J Med Libr Assoc. 2006;94(3):299-305.

8. Chattopadhyay A, Tannery NH, Silverman DAL, Bergen P, Epstein BA. Design and implementation of a library-based information service in molecular biology and genetics at the University of Pittsburgh. J Med Libr Assoc. 2006;94(3):307-13.

9. Rein DC. Developing library bioinformatics services in context: The Purdue University libraries bioinformationist program. J Med Libr Assoc. 2006;94(3):314-20.
10. Tennant MR. Bioinformatics librarian: Meeting the information needs of genetics and bioinformatics researchers. Reference Services Review. 2005;33(1):12-19. doi: 10.1108/ 00907320410519333.

11. Wang L, Lipsey K, Murray C, Prendergast N, Schoening P. The bioinformatics program at Washington University's Bernard Becker Medical Library: Making it happen. Med Ref Serv Q. 2007;26(2):87-98.

12. Yarfitz S, Ketchell DS. A library-based bioinformatics services program. Bull Med Libr Assoc. 2000;88(1):36-48.

13. Kajosalo E. Bioinformatics: An instructional opportunity for academic science and engineering libraries. Paper presented at: $232^{\text {nd }}$ American Chemical Society National Meeting, 2006 Sep 10-14; San Francisco California Available from: http:// acscinf.org/docs/meetings/232nm/presentations/232nm35.pdf.

14. Geer RC. Broad issues to consider for library involvement in bioinformatics. J Med Libr Assoc. 2006;94(3):286-98.

15. Herland K. $\$ 69$ million for infrastructure projects. 2009 Oct 15 [cited 2009 Nov 2]. In: Concordia Journal [Internet]. Montreal: Concordia University, c2009. [about 2 screens]. Available from: http://cjournal.concordia.ca/archives/20091015/69_ million_for_infrastructure_projects.php.

16. Winston MD. Academic science and engineering librarians: A research study on demographics, educational backgrounds and professional activities. Science \& Technology Libraries. 2000;19(2):3-24.

17. Hackenberg JM, Chu B. Why does one choose sci-tech librarianship? Findings of a survey. Science \& Technology Libraries. 2002;23(1):3-16.

18. Brown C. The changing face of scientific discourse: Analysis of genomic and proteomic database usage and acceptance. JASIST. 2003;54(10):926-38. doi: 10.1002/asi.10289.

19. Lyon JA, Tennant MR, Messner KR, Osterbur DL. Carving a niche: Establishing bioinformatics collaborations. $J$ Med Libr Assoc. 2006;94(3):330-5.

\section{Appendix A}

Survey sent to librarians in the biological or health sciences in Canadian Universities on October 24, 2009.

1. Do you have formal education in the sciences (for example, an undergraduate or graduate degree in the health or biological sciences)

Yes

No

2. If you answered yes to Question \#1, what kind of degree do you hold?

Undergraduate

Graduate

Other

What was the field of study? (eg. Biochemistry)

3. In your role as librarian, what subjects are you responsible for? (eg.: Molecular \& Cell Biology Librarian)

4. Is there a medical school at the university where you work?

Yes

No

5. Have professors asked you to provide workshops/classes in the use of bioinformatics databases or resources (such as GenBank or Swiss-Prot) to students within a specific class?

Yes

No 
If you answered yes, can you specify which course it was for? (eg. graduate class in medical genetics)

6. Do you provide general library workshops, not connected to any university course, in the use of bioinformatics databases or resources (such as GenBank or Swiss-Prot)?

Yes

No

If you answered yes, what was the workshop(s) topic?

7. Have you created online tutorials that show how to use bioinformatics databases or resources (such as GenBank or Swiss-Prot)?

Yes

No

If you answered yes, what was the topic of the tutorial?

8. Do you maintain a research guide or webpage specifically on bioinformatics which would contain information about resources and tools, services and workshops, etc.?

Yes

No

Comments?

9. Do you receive questions from students or faculty who may need help finding or using bioinformatics databases or resources?

Yes

No

10. If you answered Yes to Question \#8, what is the frequency with which you receive these questions?

Daily

Weekly

Monthly

Yearly

11. Do you have any additional comments to add?

\section{Appendix B}

Universities contacted to complete the survey presented in Appendix A. Asterisks indicate universities that have a medical school.

Carleton University

Dalhousie University*

McMaster University*

Memorial University*

Mount Allison University

Queen's University*

Simon Fraser University

University of Alberta*

University of British Colombia*

University of Calgary*

University of Guelph

University of Manitoba*

University of New Brunswick

University of Ottawa*

University of Prince Edward Island

University of Saskatchewan*

University of Toronto*

University of Victoria

University of Waterloo

University of Western Ontario*

York University

\section{Appendix C}

Survey sent to faculty members of the Concordia University Centre for Structural and Functional Genomics on October 22, 2009.

Tell us about yourself

1. What is your title?

2. What is your field of study? 
Article database question

1. Please mark the frequency with which you consult the following article databases:

\begin{tabular}{|c|c|c|c|c|c|}
\hline PubMed (MEDLINE) & Daily & Weekly & Monthly & Yearly & Never \\
\hline Web of Science & & & & & \\
\hline SciFinder & & & & & \\
\hline BIOSIS & & & & & \\
\hline INSPEC / Compendex & & & & & \\
\hline Other (please specify in the comments box) & & & & & \\
\hline Other (please specify in the comments box) & & & & & \\
\hline
\end{tabular}

Comments (please specify "other" databases)

\section{Bioinformatics database questions}

1. Do you use web-based bioinformatics database(s) that are publicly available on the Internet?

No (please skip questions 2-5)

Yes

Comments?

2. Please indicate the bioinformatics tools and databases you routinely use:

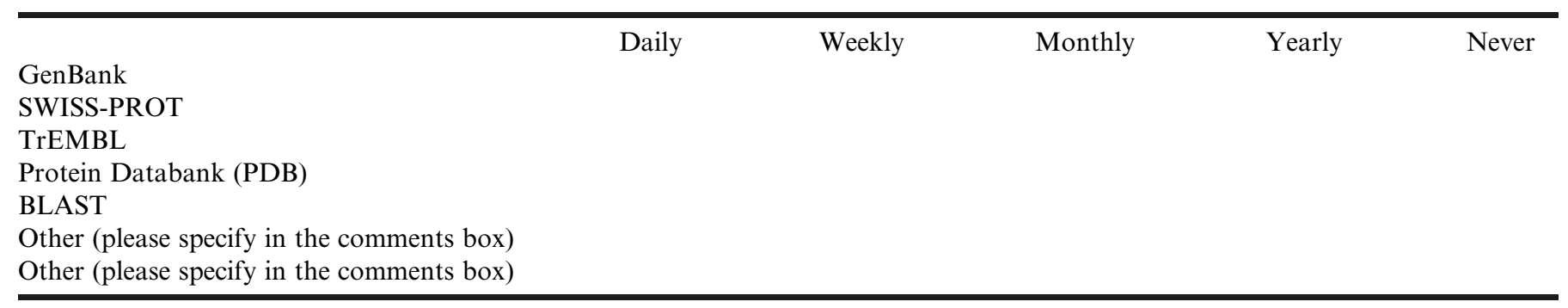

Comments (please specify "other" databases)

3. Why do you access web-based bioinformatics database(s)? (Please mark all answers that are appropriate.)

To deposit data

To compare your data to that from other laboratories

To look for newly deposited sequences and structures from other laboratories

Other (please specify)

4. Where did you learn how to use bioinformatics databases? (Please mark all answers that are appropriate.)

From graduate students in your or another laboratory?

From postdoctoral fellows in your or another laboratory?

From technicians in your or another laboratory?

In classes during graduate school or during your undergraduate studies?

Did you learn on your own?

From a librarian?

Other (please specify)

5. Have you taught the use of bioinformatics databases to: (Please mark all answers that are appropriate.)

Your colleagues

Your graduate or undergraduate students in your laboratory (if you supervise any)

Your technicians in your laboratory (if you have any)

Your graduate or undergraduate students in your classes

Other

Please specify the class(es) where you've taught this AND (OR) other people you've taught these databases to:

6. Do you believe the library should play a role in training or consulting with students or faculty in the use of bioinformatics databases (for example, by giving workshops or helping individual students with questions they may have)

Yes

No

Comments (please specify why you answered yes or no) 